\title{
SPONTANEOUS REGRESSION OF MALIGAN BREAST NEOPLASIA IN A FEMALE PATIENT WITH HIGH LEVEL OF IMMUNOGLOBULIN IG E
}

Jackson Roberto de Moura1

${ }^{1}$ Instituto da Mama de Ubá - Ubá (MG), Brazil.

M.C.V., aged 54, born in Presidente Bernardes, Minas Gerais, was admitted on 09/10/2018 with a palpable alteration in the right breast, having a $15 \mathrm{~mm}$ heterogeneous lobed nodule at the junction of the upper quadrant of the right breast (BI-RADS 5) with mammography having focal asymmetry in the same position (BI-RADS 0), being submitted to core-biopsy by ultrasound with resulting Infiltrating Ductal Carcinoma - Grade 3. Immunohistochemical pattern reveals positivity of the estrogen and progesterone hormone receptors, C-ERB B2 with a score of +2 and Ki67-positive by 20\%. Negative Fish test. She refused treatment, returning to the service on 14/08/2019 with normal physical examination, an 8 mm ultrasound lesion at the junction of the upper quadrants of the right breast (BI-RADS 6) and regression in mammography of focal asymmetry. Staging study performed with chest X-rays, total abdomen ultrasound and normal bone scintigraphy. Laboratory study was normal, except for the high level of total IgE in 4,290. She underwent segmental and sentinel lymph node resection in the right breast on 17/08/2019 at Hospital São Vicente de Paula, Ubá, Minas Gerais, with histological result, infiltrating lobular carcinoma, $9 \mathrm{~mm}$ in size, free margins and study of the negative sentinel lymph node. Radiotherapy and use of Tamoxifen $20 \mathrm{mg}$ for 5 years were indicated. It was possible to conclude that there is something different, possibly associated with the high level of IgE, which we continue to study to further understand. 